Research Article

\title{
Influence of PPA on the Short-Term Antiaging Performance of Asphalt
}

\author{
Lining Gao ${ }^{(D)},{ }^{1}$ Nana Cai, ${ }^{1}$ Xiaohong Fu, ${ }^{1}$ Rui He $\mathbb{D}^{\mathrm{D}},{ }^{1,2}$ Honggang Zhang, ${ }^{3}$ Jiayin Zhou, \\ Dongliang Kuang, ${ }^{1}$ and Shaowen Liu ${ }^{2}$
}

\author{
${ }^{1}$ School of Materials Science and Engineering, Chang'an University, Xi'an 710061, China \\ ${ }^{2}$ Shanxi Transportation Technology Research \& Development Co., Ltd., Taiyuan 030032, China \\ ${ }^{3}$ Guangxi Transportation Research Institute Co., Ltd., Nanning 530007, China
}

Correspondence should be addressed to Rui He; heruia@163.com

Received 17 November 2020; Accepted 24 January 2021; Published 3 February 2021

Academic Editor: Shaopeng Wu

Copyright (c) 2021 Lining Gao et al. This is an open access article distributed under the Creative Commons Attribution License, which permits unrestricted use, distribution, and reproduction in any medium, provided the original work is properly cited.

It has been confirmed that polyphosphoric acid (PPA) can significantly improve the high-temperature resistance, storage stability, and aging resistance of asphalt. The low price of PPA is conducive to the development of modified asphalt with high performance and excellent economy, suggesting its great application prospects. At present, there is little research on the role of PPA in delaying the aging process of PPA-modified asphalt, and a consensus has not yet been reached. Therefore, PPA-modified asphalt with different blending amounts (0 wt\%, $0.4 \mathrm{wt} \%, 0.8 \mathrm{wt} \%$, and $1.2 \mathrm{wt} \%)$ was prepared in this study. On the basis of variable performance, the role of PPA in the short-term antiaging process of asphalt is analyzed through Fourier transform infrared spectroscopy (FTIR) analysis of PPA-modified asphalt before and after aging, combined with the analysis of the change in components. The results showed that after PPA addition, the high-temperature resistance and the thermal stability of asphalt were improved and the temperature sensitivity was weakened. Both curves of ductility and $G^{*}$ indicate the potential saturation effect of PPA addition; together with infrared spectroscopy, we proved that there are both chemical reactions and physical mixing in the PPA-modified asphalt. The component fractions show that PPA will cause the asphalt to transform from sol to gel and the main function of PPA in retarding asphalt aging is the dispersion of the agglomerates of asphaltene micelles by PPA.

\section{Introduction}

Asphalt is the most typical binder material of mineral aggregate for road pavement construction and has received much attention in the past few decades [1]. However, some serious functional damage to asphalt pavement appears under heavy traffic load and severe weather conditions. For example, pavement contraction due to a temperature drop during the cold seasons increases the stiffness of the asphalt binder, which generally causes cracking. Another type of hazard observed in asphalt pavement, rutting, is a permanent distortion in the wheel path caused by traffic loads and is more common in hot seasons [2]. To overcome or mitigate the hazards of bituminous mixtures in the pavement, engineers and scientists have used different methods to improve the properties of asphalt binder and asphalt mixtures.
Many different types of polymer modifiers can be used to improve the performance of asphalt mixture pavement $[3,4]$. Among them, polyphosphoric acid (PPA) has gradually attracted researchers' attention. As a mixture of triphosphate pyrophosphate, PPA, and other advanced acids as well as inorganic compounds with high solubility [5], PPA has advantages such as low cost and simple processing technology, and it exhibits a good modification effect on asphalt [6], involving the improvement of the temperature sensitivity, high-temperature stability, and antiaging performance of matrix asphalt. Due to the above advantages of PPA, many scholars have studied it in recent decades. Baldino et al. [7] found that PPA could improve the hightemperature performance of asphalt binders through dynamic shear rheological (DSR) tests. What is more, the performance of asphalt pavement is seriously affected by the 
aging of asphalt [8]. Liu et al. [9] studied the short-term antiaging properties of four types of matrix asphalt and PPA-modified asphalt. It is observed that PPA-modified asphalt demonstrates a higher failure temperature, phase angle, $G^{*} / \sin \delta$, and zero shear viscosity after rolling thinfilm oven (RTFO) aging, indicating that the PPA-modified asphalt has a better antiaging performance. However, there are different views on the low-temperature performance and specific action mechanism of PPA-modified asphalt. Baldino et al. [10] found that the glass transition temperature decreased when PPA was mixed into asphalt, which could improve the stiffness, thus improving the low-temperature performance. However, Cao et al. [11] obtained conflicting conclusions that PPA can reduce low-temperature performance, and it is proved by Cao et al. [12] that PPA has little impact on its low-temperature performance.

Some previous studies also showed that there was still no consistent conclusion on the modification mechanism of PPA-modified asphalt. Liu et al. [13] conducted an infrared analysis of asphalt before and after the modification of PPA and found that no new absorption peak appeared, indicating that PPA only had a physical effect on asphalt. The infrared analysis conducted by Wang et al. [14] found that chemical reactions may occur in PPAmodified asphalt. Dourado et al. [15] found that there is a stronger interaction between PPA and the functional groups containing $\mathrm{C}-\mathrm{O}$ bonds. The modification effect is inconsistent and the action principle of PPA on asphalt cannot be determined may be due to the differences in the matrix asphalt, PPA content, and/or preparation process [16].

As can be seen, although the performance advantages and economic benefits have been widely proven and researchers have carried out a lot of researches on PPAmodified asphalt, some concerns remained as the effect of PPA on asphalt were not clear, such as its modification mechanism and its influence reasons on asphalt aging performance. Therefore, it is extremely necessary to carry out more detailed research and analysis. In this study, PPAmodified asphalt with different PPA contents $(0 \mathrm{wt} \%, 0.4 \mathrm{wt}$ $\%, 0.8 \mathrm{wt} \%$, and $1.2 \mathrm{wt} \%)$ was prepared. The preparation process, asphalt matrix type, and dosage have been optimized to ensure a stable performance of the PPA-modified asphalt in order to analyze the antiaging mechanism more accurately. The conventional properties and high-temperature rheological properties were studied, and the role of PPA in the antiaging process of asphalt is analyzed through FTIR analysis combined with analysis of the change in components.

\section{Materials and Methods}

2.1. Materials. In this study, $90 \#$ asphalt from Donghai (Sinopec Group, China) was used as the matrix asphalt, and the basic properties are shown in Table 1. PPA, the product of Kelon Chemical Company (China), was utilized to modify the asphalt binder. The main parameters of PPA are presented in Table 2.
TABle 1: Basic properties of 90\# Donghai asphalt.

\begin{tabular}{|c|c|c|}
\hline Parameters measured & Result & Normal value \\
\hline Penetration at $25^{\circ} \mathrm{C}(0.1 \mathrm{~mm})$ & 80.2 & $80 \sim 100$ \\
\hline Softening point $\left({ }^{\circ} \mathrm{C}\right)$ & 46.3 & $\geq 45$ \\
\hline Ductility at $10^{\circ} \mathrm{C}(\mathrm{cm})$ & 113.6 & $\geq 100$ \\
\hline Ductility at $15^{\circ} \mathrm{C}(\mathrm{cm})$ & $>100$ & $\geq 100$ \\
\hline Mass loss (\%) & 0.15 & $\leq 0.8$ \\
\hline TFOT $\left(163^{\circ} \mathrm{C}, 5 \mathrm{~h}\right) \quad$ Penetration ratio (\%) & 58 & $\geq 57$ \\
\hline Ductility at $15^{\circ} \mathrm{C}(\mathrm{cm})$ & 36 & $\geq 20$ \\
\hline
\end{tabular}

TABLe 2: Main parameters of PPA.

\begin{tabular}{lccc}
\hline $\mathrm{P}_{2} \mathrm{O}_{5}(\%)$ & Sulfate (\%) & $\mathrm{Fe}(\%)$ & Potassium permanganate (\%) \\
\hline$\geq 80.0$ & $\leq 0.005$ & $\leq 0.01$ & Qualified \\
\hline
\end{tabular}

2.2. Preparation of PPA-Modified Asphalt. To prepare PPAmodified asphalt, PPA was blended with asphalt binders. Four asphalt binders with different PPA contents ( 0 wt $\%, 0.4$ $\mathrm{wt} \%, 0.8 \mathrm{wt} \%$, and $1.2 \mathrm{wt} \%$ ) were investigated in this study. The matrix asphalt was heated at $150^{\circ} \mathrm{C}$ to ensure the flowing state. Then, PPA was added slowly and mixed for $40 \mathrm{~min}$ at the target temperature of $160^{\circ} \mathrm{C}$ with a high shear mixer at a speed of $1000 \mathrm{r} / \mathrm{min}$.

\subsection{Methods and Instruments}

2.3.1. Conventional Property Test. The penetration, softening point, ductility, and viscosity of matrix asphalt and PPAmodified asphalt were determined using the methods of ASTM D5, D113, D36, and D4402, respectively.

2.3.2. DSR Test. The dynamic shear rheological (DSR) test was carried out on a Smart Pave102 dynamic shear rheological instrument of Anton Paar (Austria). The test samples were scanned at a frequency of $10 \mathrm{rad} / \mathrm{s}$ from $46^{\circ} \mathrm{C}$ to $76^{\circ} \mathrm{C}$.

2.3.3. Four-Component Test. In order to further understand the component change of asphalt in the modification and aging process, four components of asphalt, namely, saturates, aromatics, resins, and asphaltenes, respectively, were separated by the T0618-1993 four-component test in Standard JTG E20-2011 [17].

2.3.4. TFOT. The asphalt thin-film oven test (TFOT) was used to simulate the short-term aging of asphalt. Fourier transform infrared spectra of samples were recorded by a Bruker Tensor-27 FTIR spectrometer.

2.3.5. FTIR. Fourier transform infrared spectroscopy (FTIR) measurements of all samples were carried on a Bruker Tensor II FTIR Spectrometer. The samples were measured by an attenuated total reflectance (ATR) method scanning at a range of $400 \sim 4000 \mathrm{~cm}^{-1}$. 
2.3.6. TG Test. Thermogravimetric (TG) curves were obtained by using a TA SDT650 synchronous thermal analyzer. During the experiment, a small amount of asphalt (approximately $10 \mathrm{mg}$ ) was placed into the sample dish, and the mass loss curve of the sample was measured with the change in temperature (room temperature $\sim 800^{\circ} \mathrm{C}, 10^{\circ} \mathrm{C} / \mathrm{min}$ ) in air atmosphere.

\section{Results and Discussion}

\subsection{Conventional Properties}

3.1.1. Penetration. The penetration test is used to evaluate the viscosity of the asphalt binder after modification; the higher the penetration value of the asphalt binder is, the less viscous the asphalt binder is. The penetration of asphalt binders with different PPA contents is displayed in Figure 1(a). The penetration values appear to present a linear decrease with increasing PPA content, which indicates an increase in asphalt binder stiffness and viscosity [18]. This change is due to the increase in asphaltene content with the addition of PPA, which is consistent with the results of fourcomponent experiments (cf. 3.4.1).

3.1.2. Softening Point. The softening point indicates the tendency of the asphalt binder to flow at elevated temperatures. The softening points of asphalt binders with different PPA contents are shown in Figure 1(b). Figure 1(b) shows that the softening point of asphalt binders increased with increasing PPA content. When adding $1.2 \mathrm{wt} \%$ PPA, the softening point increased from $46.3^{\circ} \mathrm{C}$ to $58.0^{\circ} \mathrm{C}$, showing that PPA has a hardening effect on asphalt, which is related to the serious transformation of asphalt structure from sol to gel [18]. This result is also supported by the decrease in penetration (cf. Figure 1(a)). Thus, the high-temperature stability of asphalt was improved with the addition of PPA.

3.1.3. Ductility. The ductility test reflects the stretching ability of the asphalt binder without breaking. The ductility of asphalt binders with different PPA contents is shown in Figure $1(\mathrm{c})$. When $0.4 \mathrm{wt} \%$ PPA was added, the ductility at $10^{\circ} \mathrm{C}$ decreased dramatically from $113.6 \mathrm{~cm}$ to $22.2 \mathrm{~cm}$, which shows that PPA is detrimental to the low-temperature crack resistance of asphalt. It is expected that the addition of more PPA into asphalt leads to a worse low-temperature deformation capacity. However, the addition of PPA from $0.4 \mathrm{wt} \%$ to $1.2 \mathrm{wt} \%$ did not cause the ductility to decline sharply, indicating that there is possibly a potential saturation mechanism on the effect of PPA, which seems to be explained by the fact that the intensity of new characteristic peaks does not increase or decrease with increasing PPA content (cf. 3.4.2).

3.1.4. Viscosity. The viscosity of asphalt binders at $135^{\circ} \mathrm{C}$ represents the fluidity of the asphalt, which is an indicator of how easily the asphalt can be pumped and mixed in the asphalt plant. The influence of PPA on asphalt viscosity is presented in Figure 1(d). Compared with that of matrix asphalt, the viscosity of 1.2 wt $\%$ PPA-modified asphalt increased more than twofold from $415 \mathrm{mPa} \cdot \mathrm{s}$ to $1020 \mathrm{mPa} \cdot \mathrm{s}$, indicating that PPA makes the asphalt more viscous, which is why the penetration decreases gradually. Although the viscosity of binders is observed to increase with increasing PPA content, the maximum viscosity values satisfy the current Superpave requirement.

3.1.5. Penetration Index (PI). The penetration of modified asphalt with different PPA contents at different temperatures is listed in Table 3 . The linear regression equation (equation (1)) was obtained by drawing the relationship curve between $\lg P$ (where $P$ stands for the penetration) and the temperature $(T)$ according to the data in Table 3. Then, the penetration index PI values were calculated by combining the following two equations:

$$
\begin{aligned}
\lg P & =K+A \cdot T, \\
\mathrm{PI} & =\frac{20-500 A}{1+50 A}-10,
\end{aligned}
$$

where $K$ and $A$ are the intercept and slope of the curve, respectively.

The PI is widely used to describe the temperature sensitivity of asphalt. The greater the penetration index PI is, the smaller the temperature sensitivity of asphalt is. The PI value of asphalt changed along with the different PPA contents, as displayed in Figure 2. The PI value of PPA-modified asphalt increased with increasing PPA content, showing that PPA can reduce the sensitivity of asphalt to temperature.

3.2. Rheological Properties. The complex shear modulus $\left(G^{*}\right)$ of PPA-modified asphalt with different PPA contents is shown in Figure 3. The $G^{*}$ reflects the shear resistance of asphalt binders under the vehicle load. The $G^{*}$ of all types of asphalt decreases with increasing temperature. The smaller the $G^{*}$ value is, the less resistant the asphalt is to deformation. The results show that PPA can enhance the deformation resistance of asphalt. In particular, the value of $G^{*}$ increases with the increase in the amount of PPA added, especially at $46^{\circ} \mathrm{C}$, from $0 \mathrm{wt} \% \mathrm{PPA}$ to $0.4 \mathrm{wt} \% \mathrm{PPA}$, which adds a large increase (approximately $9 \mathrm{kPa}$ ). However, this improvement did not last until the end. The temperature rise makes up for the difference in values between different PPA dosages. This effect may be due to the change in the colloidal structure of the asphalt gelling agent, which increases the asphaltene contents and makes the asphalt harder [19]. It can be inferred that the modification of PPA is related to temperature; the influence is smaller when the temperature is higher. Moreover, the increase range of $G^{*}$ declines gradually with increasing PPA content, especially from $0.8 \mathrm{wt} \%$ to $1.2 \mathrm{wt} \%$, which indicates that the modification effect of PPA on asphalt may have potential saturation. According to the literature, it seems that this effect is mainly caused by the decrease in micellar aggregate size as well as the increase in surface volume ratio and solvation [7]. 


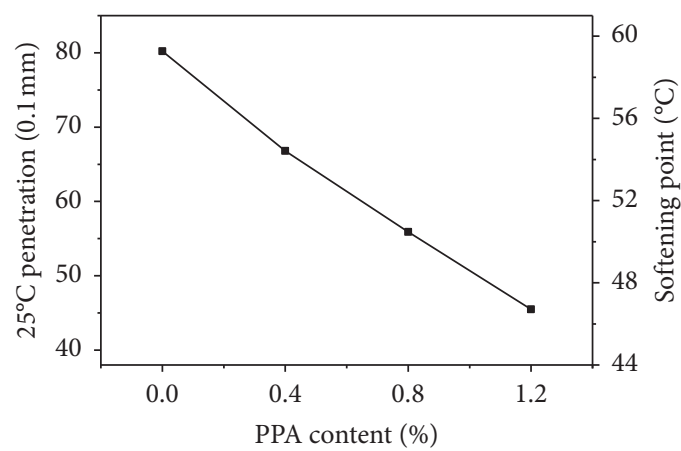

(a)

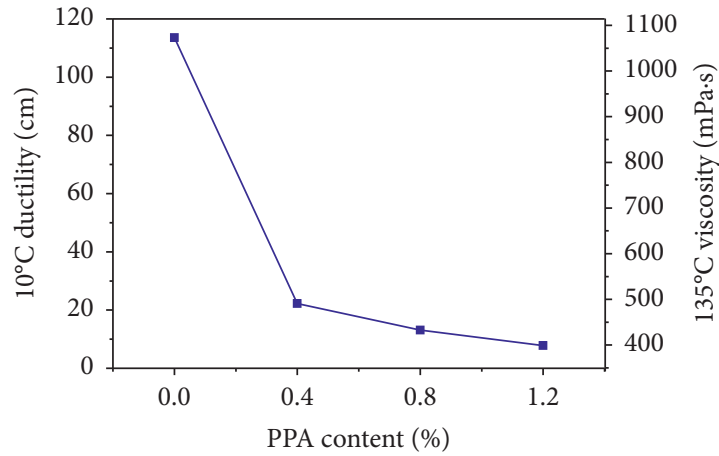

(c)

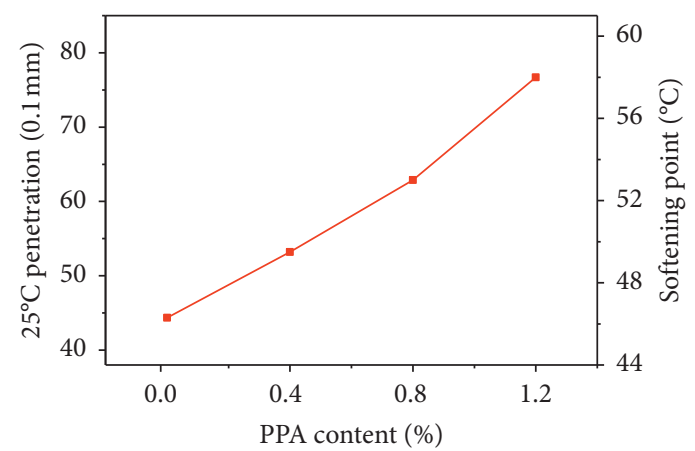

(b)

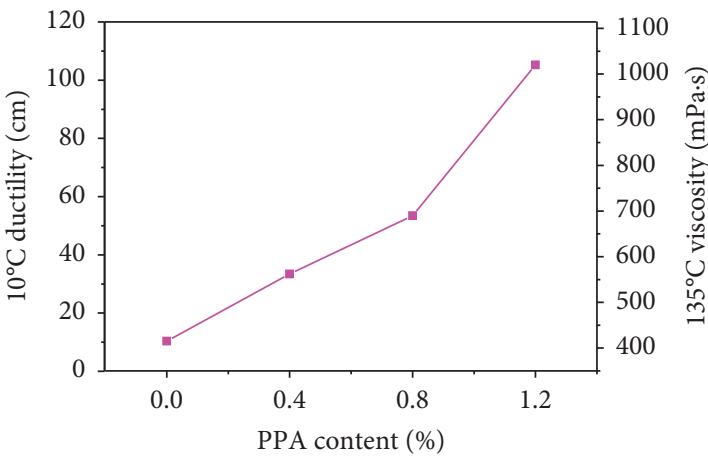

(d)

FIGURE 1: Effect of PPA content on conventional properties: (a) penetration at $25^{\circ} \mathrm{C}$, (b) softening point, (c) $10^{\circ} \mathrm{C}$ ductility, and (d) viscosity at $135^{\circ} \mathrm{C}$.

TABle 3: Penetration of PPA-modified asphalt.

\begin{tabular}{lc}
\hline Penetration $(0.1 \mathrm{~mm})$ & $0 \% \mathrm{PPA}$ \\
\hline $15^{\circ} \mathrm{C}$ & 33.4 \\
$25^{\circ} \mathrm{C}$ & 80.2 \\
$30^{\circ} \mathrm{C}$ & 122.3
\end{tabular}

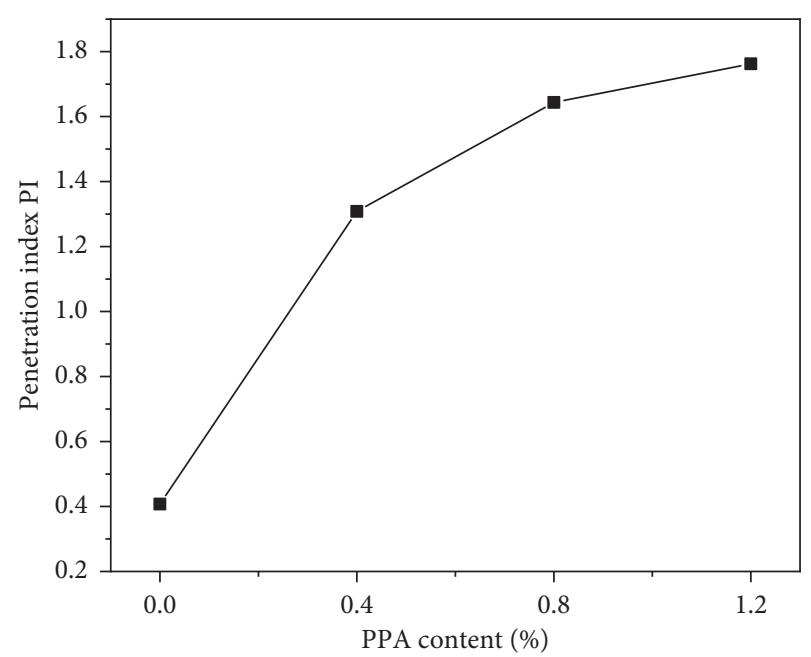

FIGURE 2: Effect of PPA content on the penetration index of asphalt.

The phase angle $\delta$ is defined as the lag between the applied shear stress and the resulting shear strain, reflecting the viscosity and elasticity of asphalt. Asphalt with a smaller

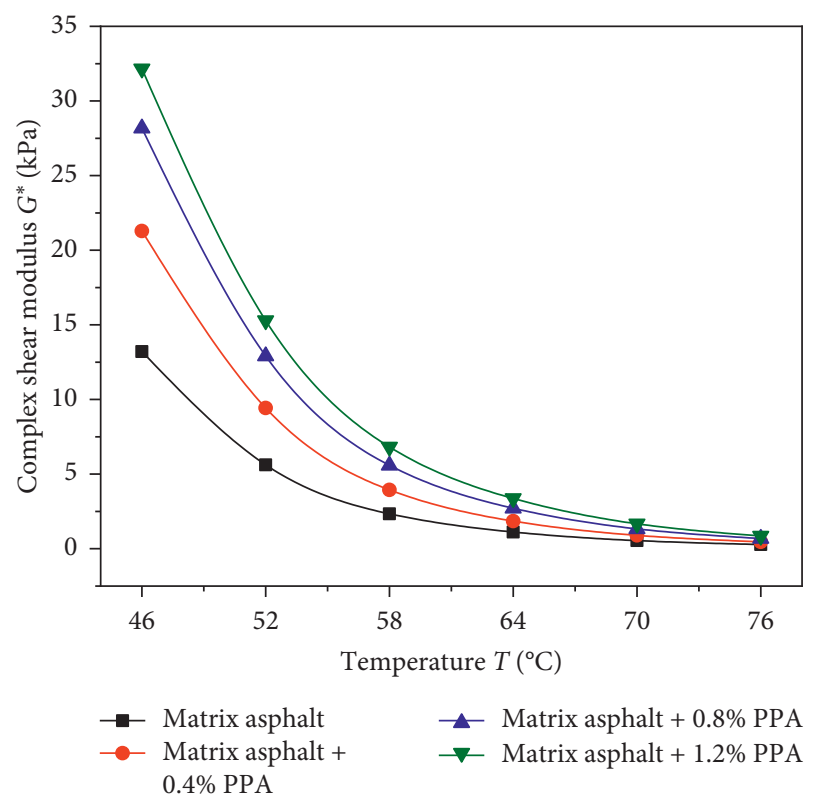

Figure 3: Effect of PPA content on the complex shear modulus $G^{*}$ of PPA-modified asphalt.

phase angle $\delta$ indicates a better elastic recovery property. The change in $\delta$ of asphalt with different PPA contents is shown in Figure 4. As can be seen from the result, the $\delta$ value of asphalt binders increased with increasing temperature, indicating that the elastic content of asphalt 


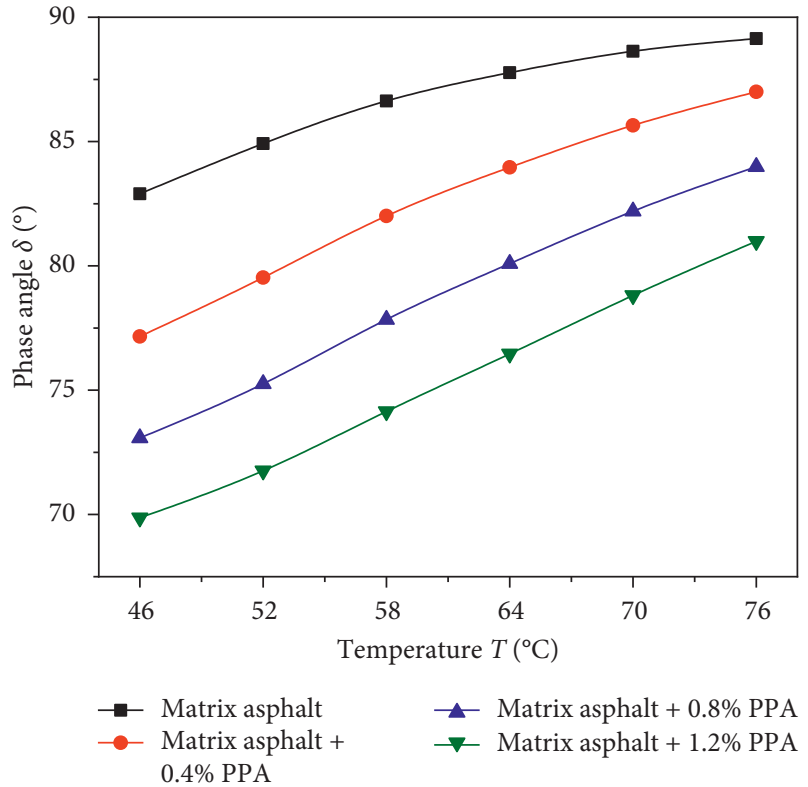

Figure 4: Effect of PPA content on the phase angle of PPAmodified asphalt.

decreases and that its resistance to deformation is weakened. For asphalt modified with a higher PPA content, the $\delta$ value decreased at the same test temperature, showing that the elastic content is increased and that the antideformation ability is enhanced.

Obviously, with increasing PPA content, the resulting rheological properties are significantly improved, indicating that the permanent deformation is lower at a higher modification level. Considering the relative changes in $G^{*}$ and $\delta$ caused by the modification $\left(G^{*}\right.$ increased by $143 \%$ while B decreased by 15\%), the main effect of PPA is the change in the rigidity of the asphalt binder measured by $G^{*}$, and the secondary effect is the change in elasticity measured by $\delta$, which is consistent with the literature [20]. Similarly, with the increase of PPA content, the degree of influence on $\delta$ decreases, which is consistent with $G^{*}$ and ductility.

3.3. Antiaging Performance. In this paper, the residual penetration ratio (RPR), softening point difference $(\Delta T)$, ductility retention rate (DRR), and viscosity aging rate (VAR) were selected to reflect the aging degree of asphalt. RPR, $\Delta T$, DRR, and VAR are defined as equations (3)-(6), respectively:

$$
\begin{aligned}
\mathrm{RPR} & =\frac{P_{\text {aged }}}{P_{\text {unaged }}} \times 100 \%, \\
\Delta T & =T_{\text {aged }}-T_{\text {unaged }}, \\
\mathrm{DRR} & =\frac{D_{\text {unaged }}-D_{\text {aged }}}{D_{\text {unaged }}} \times 100 \%, \\
\mathrm{VAR} & =\frac{V_{\text {aged }}-V_{\text {unaged }}}{V_{\text {unaged }}} \times 100 \%,
\end{aligned}
$$

where $P, T, D$, and $V$ represent the penetration at $25^{\circ} \mathrm{C}$, the softening point, the ductility at $10^{\circ} \mathrm{C}$, and the viscosity at $135^{\circ} \mathrm{C}$, respectively. The specific data of the four parameters of PPA-modified asphalt before and after aging are listed in Table 4. Thus, RPR, $\triangle T$, DRR, and VAR can be calculated based on these data. The larger the value of RPR and DRR is, the smaller the $\Delta T$ and VAR are, and the better the antiaging performance of PPA-modified asphalt.

The changes in RPR, $\triangle T$, DRR, and VAR with the PPA content are shown in Figure 5. It can be seen from the figure that, with increasing PPA content, RPR and DRR increase continuously, while $\Delta T$ and VAR change following the opposite pattern. When the PPA content increased from 0 wt $\%$ to 1.2 wt $\%$, RPR increased from $58 \%$ to $97 \%, \Delta T$ decreased from $7.5^{\circ} \mathrm{C}$ to $2.2^{\circ} \mathrm{C}$, DRR increased from $13 \%$ to $82 \%$, and VAR decreased from $49.4 \%$ to $11.8 \%$. These results showed that PPA is beneficial to the antiaging performance of asphalt.

\subsection{Microscopic Analysis}

3.4.1. Four-Component Test. In recent decades, asphalt has been considered a resin containing micelles, in which asphaltene is identified as the micellar center surrounded by a layer of low molecular weight hydrocarbons dispersed in the oil phase [21]. The influence of PPA on the asphalt composition is presented in Figure 6. It is clearly observed that the asphaltene content is increasing and that the resin content is decreasing, while the saturates and aromatics remain almost unchanged with increasing PPA content. Orange et al. [22] believed that the variation in the asphalt component was caused by the mixing reaction of PPA with asphalt. Varanda et al. [23] revealed that, in general, PPA modification increased the fraction of asphaltenes in asphalt and decreased the saturated and resin fraction abundance, which is explained as PPA is hydrolyzed back to phosphoric acid and reacts with bitumen, probably in the form of charge transfer complexes with polycondensed aromatic structures, while PPA disrupts the agglomerates of asphaltene micelles, which promotes the distribution of asphaltenes in the maltene phase, thereby increasing the content of the aromatic fraction. However, the content of the aromatic fraction hardly increased in this study, combined with the changes of other compositions, which shows that it is impossible to conclude that the addition of PPA will destroy the agglomeration of asphaltenes.

The changes in the components of asphalt before and after aging are shown in Figure 7. The results showed that the heavy component of asphalt increased after aging for both types of asphalt, which is mainly due to oxidation and thermal oxidation. The transformation degree of PPAmodified asphalt is slightly less than that of matrix asphalt, indicating that PPA slows the aging of asphalt to a certain extent. Moreover, the increased resin content and decreased amount of saturates for both types of asphalt after aging are basically the same, while the increase rate of the asphaltene content and the decrease rate of the aromatic content in PPA-modified asphalt after aging are less than those of 
TABLe 4: Three indexes and viscosity of PPA-modified asphalt before and after aging.

\begin{tabular}{|c|c|c|c|c|c|}
\hline Parameters measured & & $0 \%$ PPA & $0.4 \% \mathrm{PPA}$ & $0.8 \% \mathrm{PPA}$ & $1.2 \% \mathrm{PPA}$ \\
\hline \multirow{2}{*}{ Penetration at $25^{\circ} \mathrm{C}(0.1 \mathrm{~mm})$} & Unaged & 80.2 & 66.8 & 55.9 & 45.5 \\
\hline & Aged & 46.5 & 51.5 & 46.7 & 44.1 \\
\hline \multirow{2}{*}{ Softening point $\left({ }^{\circ} \mathrm{C}\right)$} & Unaged & 46.3 & 49.5 & 53.0 & 58.0 \\
\hline & Aged & 53.8 & 54.0 & 56.0 & 60.2 \\
\hline \multirow{2}{*}{ Ductility at $10^{\circ} \mathrm{C}(\mathrm{cm})$} & Unaged & 113.6 & 22.2 & 13.1 & 7.8 \\
\hline & Aged & 98.3 & 14.3 & 7.2 & 1.4 \\
\hline \multirow{2}{*}{ Viscosity at $135^{\circ} \mathrm{C}(\mathrm{mPa} \cdot \mathrm{s})$} & Unaged & 415.0 & 562.0 & 690.0 & 1020.0 \\
\hline & Aged & 620.0 & 750.0 & 830.0 & 1140.0 \\
\hline
\end{tabular}

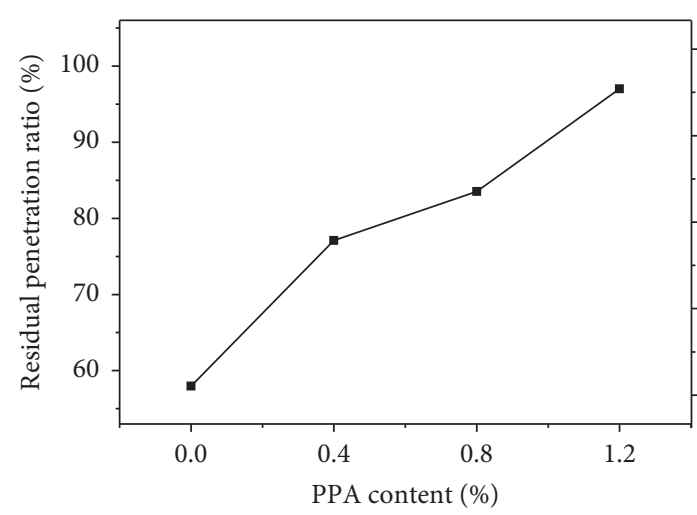

(a)

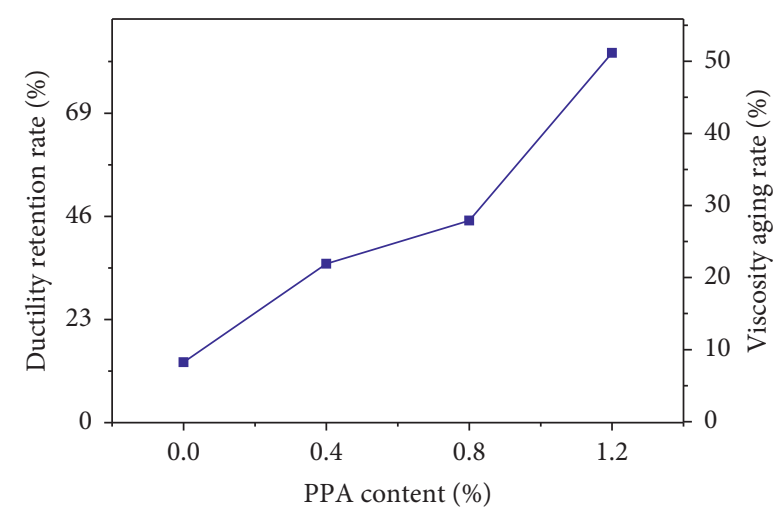

(c)
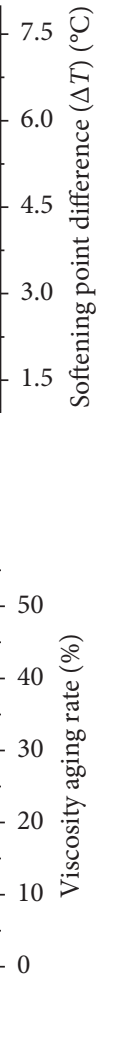

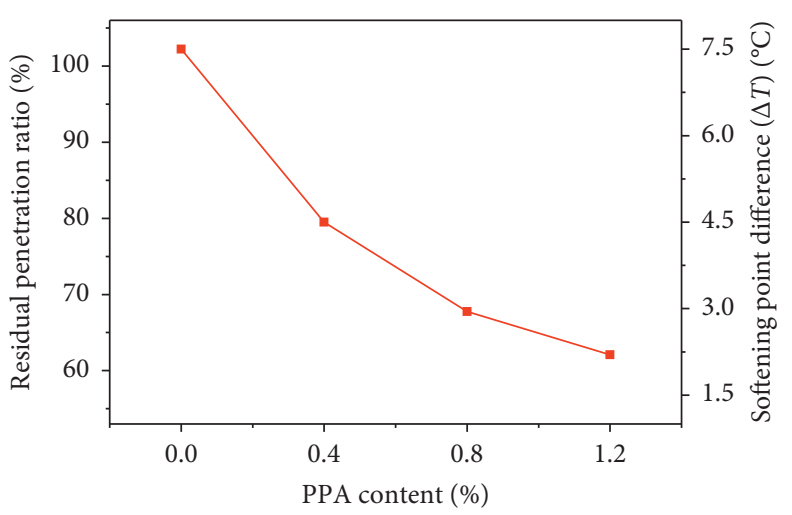

(b)

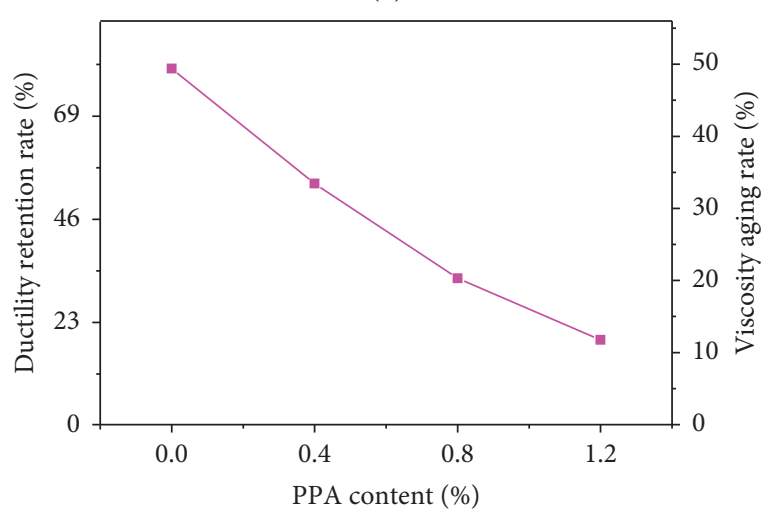

(d)

Figure 5: Effect of PPA content on (a) RPR, (b) $\Delta T$, (c) DRR, and (d) VAR.

matrix asphalt. Obviously, the effect of PPA on the aging performance of asphalt mainly lies in asphaltenes and aromatics. These observed results are principally attributed to the fact that PPA improves the oxidation stability of the bitumen blends and increases the concentration of condensed structures [23] and the deflocculation of the asphaltene fraction caused by PPA addition [24]. Therefore, combining with Figure 6, the addition of PPA will not play a role in antiflocculation of asphalt at the beginning but will play a role in the aging process, delaying the aging of asphalt.

3.4.2. Infrared Analysis. It is well accepted that the macroproperties of modified asphalt depend on its microstructure. Accordingly, the variation in the macroproperties of modified asphalt induced by the addition of PPA can be attributed to changes in the microstructure. The FTIR spectra were obtained for PPA and asphalt before and after PPA addition, as presented in Figures 8 and 9. In the FTIR spectrum of PPA (Figure 8), the broad and middle peaks near $2748 \mathrm{~cm}^{-1}$ belong to the stretching vibrations of $-\mathrm{OH}$ in PPA, and the peak of $1620 \mathrm{~cm}^{-1}$ is ascribed to the bending vibrations in the $-\mathrm{OH}$ plane. Moreover, the peak at $1205 \mathrm{~cm}^{-1}$ is attributed to $\mathrm{P}=\mathrm{O}$ tensile vibrations, the peaks at $904 \mathrm{~cm}^{-1}, 761 \mathrm{~cm}^{-1}$ and $690 \mathrm{~cm}^{-1}$ are from asymmetric vibrations of $\mathrm{P}-\mathrm{O}-\mathrm{P}$, and a bending vibration band of $\mathrm{P}-\mathrm{O}-\mathrm{P}$ can be observed at $445 \mathrm{~cm}^{-1}$ [25].

In the FTIR spectrum of matrix asphalt (Figure 9), the absorption peaks at $2919 \mathrm{~cm}^{-1}$ and $2850 \mathrm{~cm}^{-1}$ are identified as the asymmetric and symmetric $\mathrm{C}-\mathrm{H}$ stretching vibrations, 


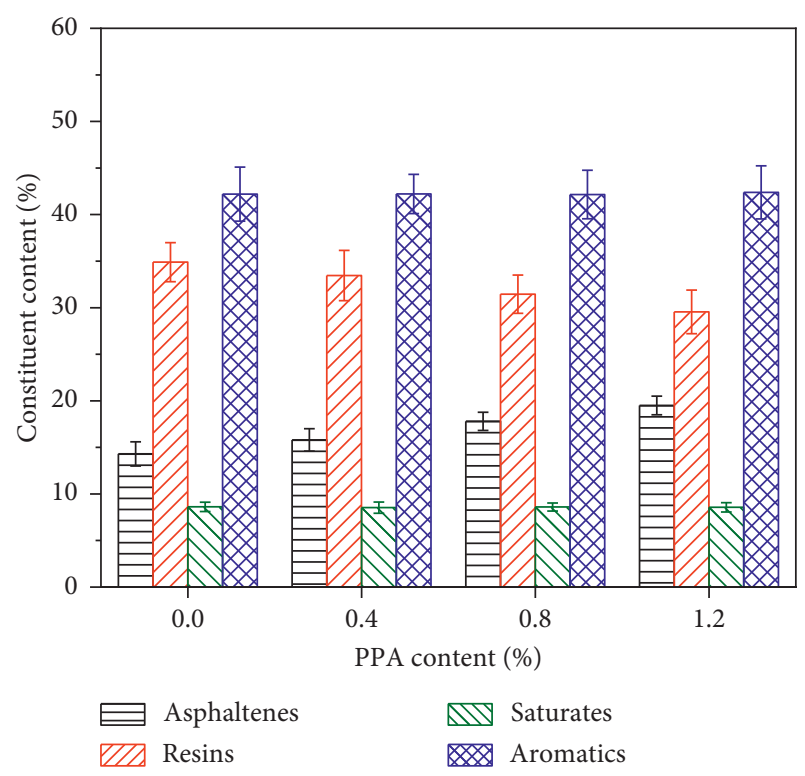

FIGURE 6: Effect of PPA content on the four-component results of asphalt.

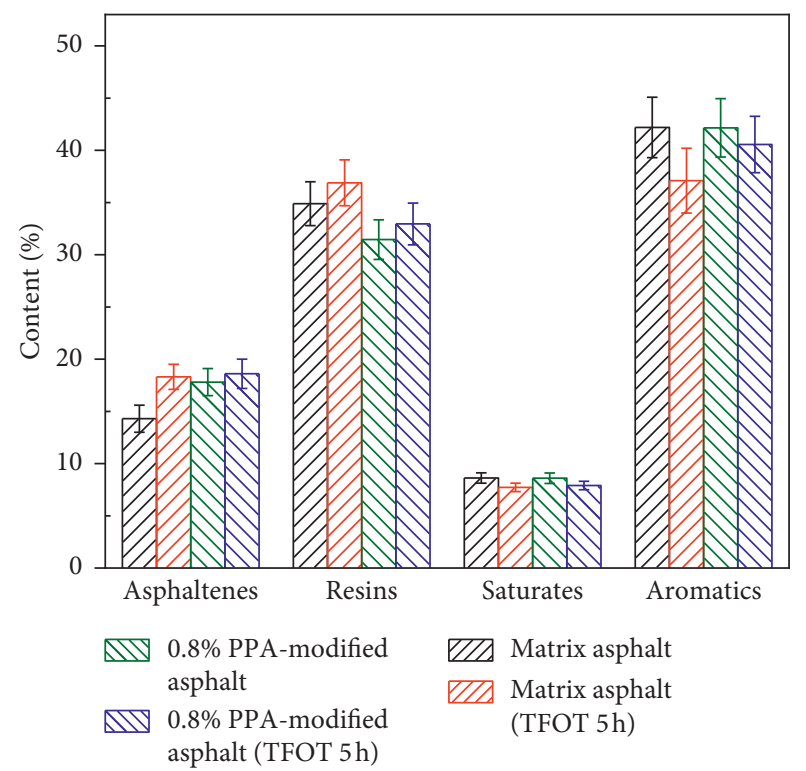

FIGURE 7: Variation of four components before and after aging of matrix asphalt and PPA-modified asphalt.

respectively [26]. The peak at $1597 \mathrm{~cm}^{-1}$ was due to aromatic $\mathrm{C}=\mathrm{C}$ stretching vibrations. The signal of $\mathrm{C}-\mathrm{H}$ bonds found at $1455 \mathrm{~cm}^{-1}$ was attributed to asymmetric deformation in $\mathrm{CH}_{2}$ and $\mathrm{CH}_{3}$, and the peak of $\mathrm{C}-\mathrm{H}$ bonds observed at $1373 \mathrm{~cm}^{-1}$ was classified as symmetric deformation vibrations in $\mathrm{CH}_{3}$. The small peaks at $811 \mathrm{~cm}^{-1}$ and $725 \mathrm{~cm}^{-1}$ were from the $\mathrm{C}-\mathrm{H}$ vibrations of the benzene ring.

The spectra did not present significant changes in the bands in the 4000 2000 $\mathrm{cm}^{-1}$ region, as observed in Figure 9. However, the spectrum that lies in this region exhibits obvious differences: first, the characteristic peaks at $2748 \mathrm{~cm}^{-1}$ and $1620 \mathrm{~cm}^{-1}$ belonging to $\mathrm{P}-\mathrm{OH}$ did not appear

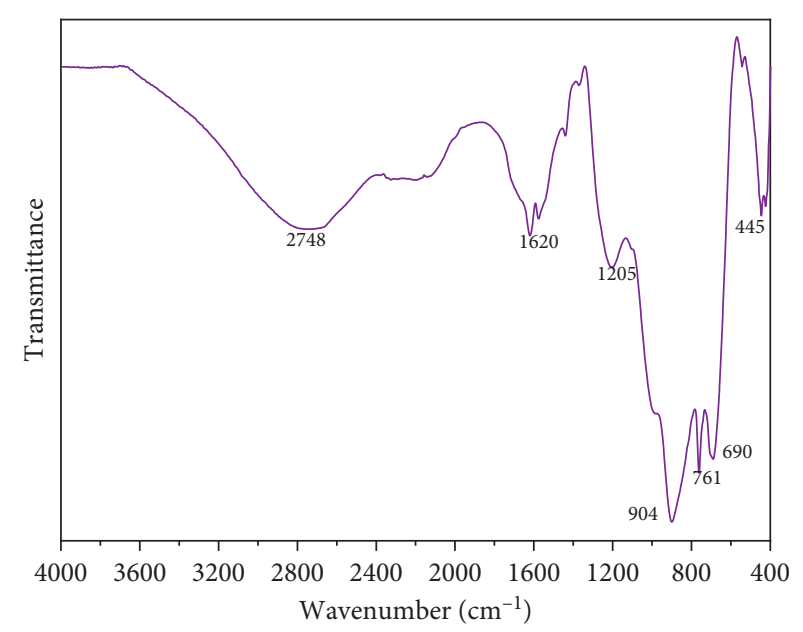

FIgURE 8: FTIR spectrum of PPA.

in the asphalt, indicating that - $\mathrm{OH}$ groups may have reacted with some groups in the asphalt; and second, PPA-modified asphalt presented a new peak in the range of $497 \sim 511 \mathrm{~cm}^{-1}$ attributed to the bending vibrations of P-O-P [27]. Moreover, the modified asphalt binder has a wider absorption peak at $1027 \mathrm{~cm}^{-1}$ that may be caused by the overlapping of adjacent weak peaks corresponding to P-O-C symmetrical stretching, which is caused by the phosphorylation of some molecular groups [28]. With increasing PPA content, the intensity of the $\mathrm{P}-\mathrm{O}-\mathrm{C}$ signals in the modified asphalt binder gradually increased. Furthermore, multiple peaks near $800 \mathrm{~cm}^{-1}$ are blue-shifted slightly, indicating that the originally strongest absorption peak of $\mathrm{P}-\mathrm{OH}$ in PPA transforms into $\mathrm{P}-\mathrm{O}-\mathrm{C}$ antisymmetric stretching in phosphate $(\mathrm{RO})_{3} \mathrm{P}=\mathrm{O}$, and it is clear that PPA chemically reacts with asphalt [26]. The above results proved that PPA may have reacted with some groups in asphalt, which is consistent with the increase in the asphaltene content.

The mechanism of asphalt aging mainly involves thermal oxygen aging. During the aging process, the carbon chains break, and oxygen reacts to form carbonyl groups and a large number of sulfoxide groups; among them, sulfoxides are the major oxidation product that controls the viscosity increase [29].

The FTIR spectra of asphalt modified with different PPA contents after aging are shown in Figure 10. From this figure, it can be observed that there is a slight change in the intensity of the peak at $1030 \mathrm{~cm}^{-1}$ attributed to the vibration of the sulfoxide group $\mathrm{S}=\mathrm{O}$ [30]. Sulfoxide production is related to the sulfur content of asphalt. The sulfoxide index $I_{\mathrm{S}=\mathrm{O}}$ is calculated by the percentage of the absorption peak area near $1030 \mathrm{~cm}^{-1}\left(936 \sim 1090 \mathrm{~cm}^{-1}\right.$, which is shown in the dashed border in Figure 10) to the absorption peak area in the range of $1457 \sim 1375 \mathrm{~cm}^{-1}$. The sulfoxide index $I_{\mathrm{S}=\mathrm{O}}$ of PPA-modified asphalt before and after TFOT aging is shown in Table 5. After aging, the sulfoxide index $I_{\mathrm{S}=\mathrm{O}}$ increases slightly for both types of asphalt with different PPA dosages, which is an inevitable and intuitive result. The larger the sulfoxide index is, the more functional groups there are. An increased number of 


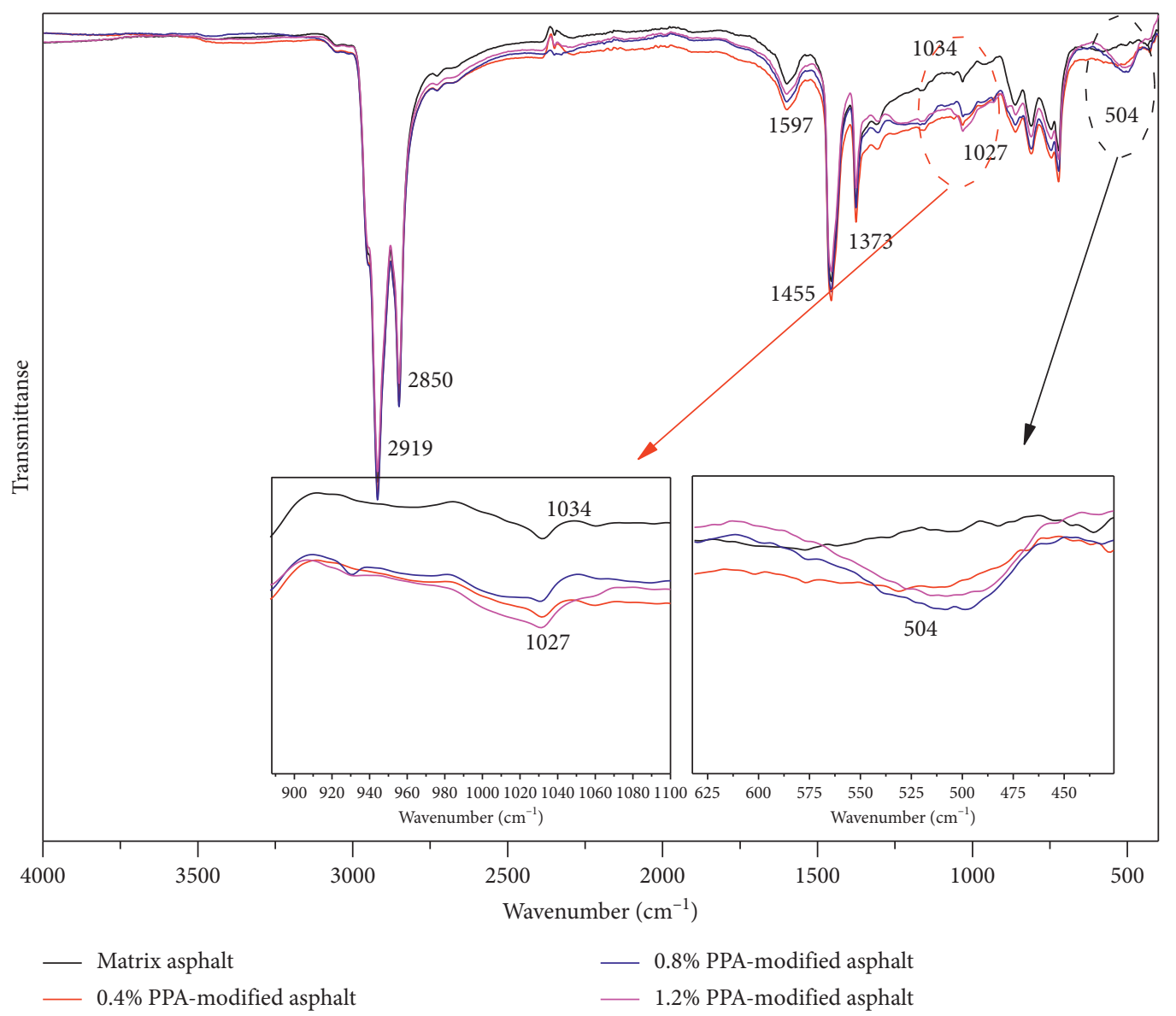

FIGURE 9: FTIR spectra of matrix asphalt and modified asphalt with different PPA contents (insets are the magnified spectra near $1027 \mathrm{~cm}^{-1}$ and $504 \mathrm{~cm}^{-1}$ ).

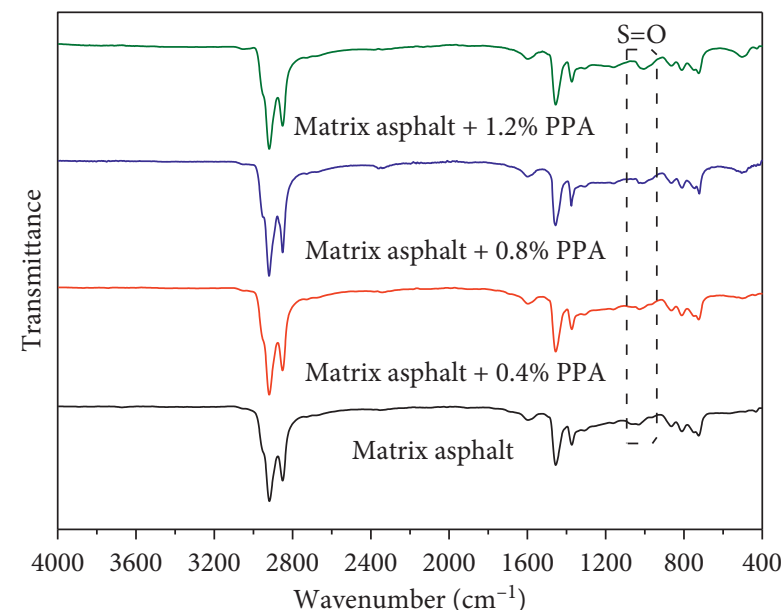

FIGURE 10: FTIR spectra of modified asphalt with different PPA content after TFOT aging (which showed in the dashed border denoted for the selected range of near $1030 \mathrm{~cm}^{-1}$ ).

sulfoxide groups will enhance the dipole correlation degree in asphalt, which is conducive to increasing the viscosity and stability of asphalt. Obviously, it can be observed from Table 5 that, as the content of PPA increases, the gap between the sulfoxide index before and after asphalt aging becomes smaller and smaller, which indicates that PPA may have a possible effect on antiaging.

Thus, to evaluate the effect of PPA on asphalt aging, the sulfoxide index change rate (SCR) after TFOT aging can be used to evaluate the degree of aging from a microscopic perspective. The SCR is defined as follows [31, 32]:

$$
\mathrm{SCR}=\frac{I_{\mathrm{S}=\mathrm{O}}(\text { aged })-I_{\mathrm{S}=\mathrm{O}}(\text { unaged })}{I_{\mathrm{S}=\mathrm{O}}(\text { unaged })} \times 100 \%
$$

Table 5 shows that the SCR continues to decrease with increasing PPA content, verifying from a microscopic perspective that PPA can improve the antiaging performance of asphalt. This result is consistent with the changes in asphalt components after aging.

3.4.3. TG Analysis. TG curves of matrix asphalt and modified asphalt with $0.8 \%$ PPA are shown in Figure 11. It can be observed from the figure that the trends of the two curves are similar. The weight loss occurs at $250 \sim 500^{\circ} \mathrm{C}$, which is mainly caused by the thermal decomposition of asphaltenes and the volatilization of light components [33]. The addition of PPA can slightly reduce the weight loss rate of asphalt, resulting in less weight loss by the end of the process. When the temperature increased from room 
TABLE 5: Sulfoxide index and sulfoxide index change rate of modified asphalt with different PPA content before and after TFOT aging.

\begin{tabular}{|c|c|c|c|c|}
\hline Parameters & $0 \% \mathrm{PPA}$ & $0.4 \% \mathrm{PPA}$ & $0.8 \%$ PPA & $1.2 \% \mathrm{PPA}$ \\
\hline$I_{\mathrm{S}=\mathrm{O}}$ (unaged) & 0.0294 & 0.0435 & 0.0552 & 0.0740 \\
\hline$I_{\mathrm{S}=\mathrm{O}}($ aged $)$ & 0.0348 & 0.0451 & 0.0561 & 0.0741 \\
\hline SCR & 18.37 & 3.68 & 1.63 & 0.14 \\
\hline
\end{tabular}

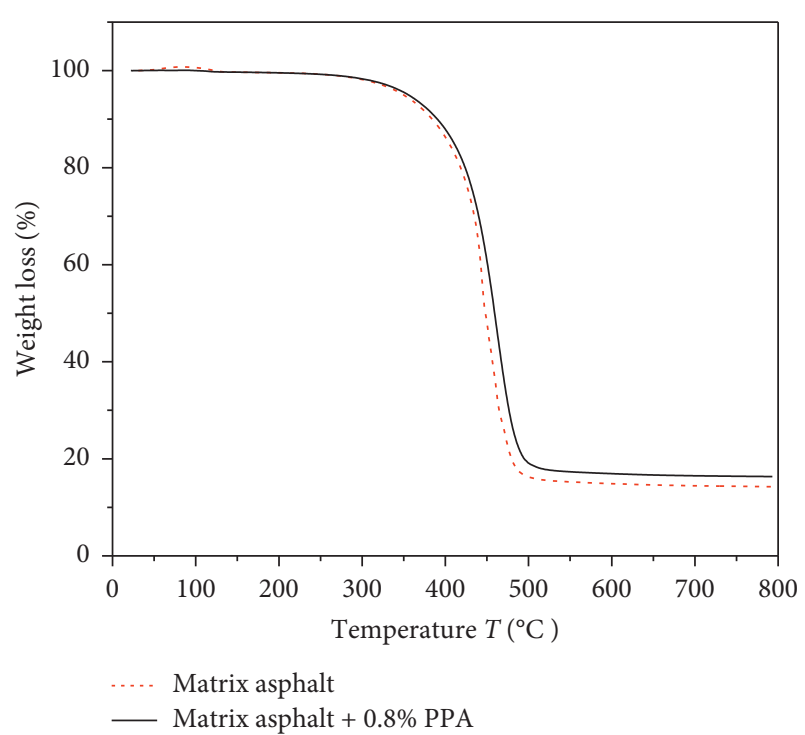

FIGURE 11: TG results of matrix asphalt and PPA-modified asphalt.

temperature to $800^{\circ} \mathrm{C}$, the remaining mass of matrix asphalt was $14.26 \%$, and the mass loss was $85.74 \%$, while the remaining mass of the asphalt became $16.34 \%$ with a mass loss of $83.66 \%$ when $0.8 \%$ PPA was added. The lower mass loss of PPA-modified asphalt is due to the increasing heavy component content in PPA-modified asphalt, which increases the phase transition temperature of the asphalt.

\section{Conclusions}

In this paper, several different amounts of PPA-modified asphalt were prepared. The purpose was to observe the role of PPA in improving high-temperature stability and antiaging processes through changes in microstructure and composition. The following conclusions are obtained:

(1) As the content of PPA increases, the penetration of modified asphalt decreases, the softening point increases, and the viscosity increases, indicating that the addition of PPA makes the asphalt thick and improves the high-temperature resistance. At the same time, the penetration index PI increases with increasing PPA content, indicating that the temperature sensitivity of PPA-modified asphalt is weakened. However, the decrease in ductility at $10^{\circ} \mathrm{C}$ indicates that excessive PPA may be harmful to lowtemperature crack resistance.

(2) Considering the relative changes in $G^{*}$ and $\delta$ caused by the modification, the rheological properties of the modified asphalt have been significantly improved, indicating that the permanent deformation is lower at a higher modification level and that the main effect of PPA involves changing the rigidity of the asphalt binder, as measured by $G^{*}$. TG analysis further showed that the initial degradation temperature of PPA-modified asphalt increased, the degradation rate slowed, and the mass loss decreased, indicating that after PPA addition, the thermal stability of asphalt was improved.

(3) Addition of PPA improves the antiaging performance of asphalt according to the results of the sulfoxide group index $I_{\mathrm{S}=\mathrm{O}}, \mathrm{RPR}, \mathrm{DRR}, \mathrm{VAR}, \Delta T$, and component fractions of matrix asphalt and PPAmodified asphalt before and after TFOT aging, which can be explained by the four-component test and FTIR analysis. The component fractions show that PPA will cause the asphalt to transform from sol to gel, consistent with the chemical reaction of PPA and asphalt observed by infrared spectra. In addition, in this study, the dispersing effect of PPA on asphaltene is more reflected in the aging process, which obviously delays the aging of asphalt.

(4) Both curves of ductility and $G^{*}$ indicate the potential saturation effect of PPA addition, which appears to explain why the peak of P-O-P is almost the same in the infrared spectra as the PPA content increases. That is, both chemical reactions and physical mixing occur in PPA-modified asphalt.

\section{Data Availability}

All data used to support the findings of this study are included within the article. More detailed data can be made available from the corresponding author upon request.

\section{Conflicts of Interest}

The authors declare that there are no conflicts of interest regarding the publication of this paper.

\section{Acknowledgments}

This research was funded by the Science and Technology Plan Projects in Guangxi Province (AA18242032), China Postdoctoral Science Foundation (2019M663602), Key Research and Development Program of Shaanxi Province (2018SF-403 and 2018SF-380), the Basic Research Project of Natural Science in Shaanxi Province (2019JQ-559 and 2019JQ-380), Science and Technology Project of Shanxi Transportation Holdings Group Co., Ltd. (18-JKKJ-16), Transportation Science and Technology Projects in Shaanxi Province (19-21K), and National Training Program of 
Innovation and Entrepreneurship for Undergraduates (S202010710159).

\section{References}

[1] G. Polacco, S. Filippi, F. Merusi, and G. Stastna, "A review of the fundamentals of polymer-modified asphalts: asphalt/ polymer interactions and principles of compatibility," Advances in Colloid and Interface Science, vol. 224, pp. 72-112, 2015.

[2] F. Zhang and J. Yu, "The research for high-performance SBR compound modified asphalt," Construction and Building Materials, vol. 24, no. 3, pp. 410-418, 2010.

[3] C. Wekumbura, J. Stastna, and L. Zanzotto, "Destruction and recovery of internal structure in polymer-modified asphalts," Journal of Materials in Civil Engineering, vol. 19, no. 3, pp. 227-232, 2007.

[4] R. He, S. Zheng, H. Chen, and D. Kuang, "Investigation of the physical and rheological properties of Trinidad lake asphalt modified bitumen," Construction and Building Materials, vol. 203, pp. 734-739, 2019.

[5] D. Singh, A. Habal, P. K. Ashish, and A. Kataware, "Evaluating suitability of energy efficient and anti-stripping additives for polymer and polyphosphoric acid modified asphalt binder using surface free energy approach," Construction and Building Materials, vol. 158, pp. 949-960, 2018.

[6] Y. Wei, Research on the Performance and Microstructure of Polyphosphoric Acid Modified Asphalt, Kunming University of Science and Technology, Kunming, China, 2015.

[7] N. Baldino, D. Gabriele, F. R. Lupi, C. Oliviero Rossi, P. Caputo, and T. Falvo, "Rheological effects on bitumen of polyphosphoric acid (PPA) addition," Construction and Building Materials, vol. 40, pp. 397-404, 2013.

[8] H. Zhang, Z. Chen, G. Xu, and C. Shi, "Evaluation of aging behaviors of asphalt binders through different rheological indices," Fuel, vol. 221, pp. 78-88, 2018.

[9] X. Liu, T. Li, and H. Zhang, "Short-term aging resistance investigations of polymers and polyphosphoric acid modified asphalt binders under RTFOT aging process," Construction and Building Materials, vol. 191, pp. 787-794, 2018.

[10] N. Baldino, D. Gabriele, C. O. Rossi, L. Seta, F. R. Lupi, and P. Caputo, "Low temperature rheology of polyphosphoric acid (PPA) added bitumen," Construction and Building Materials, vol. 36, pp. 592-596, 2012.

[11] X. Cao, Z. Zhang, P. Hao et al., "Effect of polyphosphoric acid on the high-and-low temperature property of matrix asphalt mixture," Journal of Wuhan University of Technology, vol. 36, no. 6, pp. 47-53, 2014.

[12] W. D. Cao, S. T. Liu, and H. L. Mao, "Experimental study on polyphosphoric acid (PPA) modified asphalt binders," Advanced Materials Research, vol. 152-153, pp. 288-294, 2011.

[13] B. Liu, J. Wu, H. Chen, and R. He, "Road performance and mechanism analysis of polyphosphoric acid modified asphalt," Journal of Shenzhen University Science and Engineering, vol. 35, no. 3, pp. 292-298, 2018.

[14] L. Wang, M. Ren, and C. Li, "Modification mechanism of polyphosphoric acid modified asphalt," Acta Materiae Compositae Sinica, vol. 34, pp. 2330-2336, 2017.

[15] E. R. Dourado, B. S. Pizzorno, L. M. G. Motta, R. A. Simao, and L. F. M. Leite, "Analysis of asphaltic binders modified with PPA by surface techniques," Journal of Microscopy, vol. 254, no. 3, pp. 122-128, 2014.
[16] X. Liu, Z. Zhang, X. Yang et al., "Status quo and future prospect of polyphosphoric-acid-modified asphalt," Materials Reports A, vol. 31, no. 10, pp. 104-111, 2017.

[17] Ministry of Transport of the People's Republic of China, Standard Test Methods of Bitumen and Bituminous Mixtures for Highway Engineering JTG E20-2011, China Communications Press, Beijing, China, 2011.

[18] S. Liu, S. Zhou, and A. Peng, "Evaluation of polyphosphoric acid on the performance of polymer modified asphalt binders," Journal of Applied Polymer Science, vol. 137, no. 34, p. 48984, 2020.

[19] H. Liu, M. Zhang, Y. Wang, Z. Chen, and P. Hao, "Rheological properties and modification mechanism of polyphosphoric acid-modified asphalt," Road Materials and Pavement Design, vol. 21, no. 4, pp. 1078-1095, 2018.

[20] M. Jafari, A. Akbari Nasrekani, M. Nakhaei, and A. Babazadeh, "Evaluation of rutting resistance of asphalt binders and asphalt mixtures modified with polyphosphoric acid," Petroleum Science and Technology, vol. 35, no. 2, pp. 141-147, 2017.

[21] S. Li, Q. Lin, and S. Dong, "Progress in mechanism of SBS modified asphalts," Chinese Polymer Bulletin, vol. 21, no. 5, pp. 14-19, 2008.

[22] G. Orange, D. Dupuis, and J. V. Marin, "Chemical modification of bitumen through polyphosphoric acid: propertiesmicro-structure relationship," in Proceedings of the $3 \mathrm{rd}$ Eurasphalt and Eurobitume Congress, Vienna, Austria, 2004.

[23] C. Varanda, I. Portugal, J. Ribeiro, A. M. S. Silva, and C. M. Silva, "Influence of polyphosphoric acid on the consistency and composition of formulated bitumen: standard characterization and NMR insights," Journal of Analytical Methods in Chemistry, vol. 2016, Article ID 2915467, 16 pages, 2016.

[24] P. Liang, M. Liang, W. Fan, Y. Zhang, C. Qian, and S. Ren, "Improving thermo-rheological behavior and compatibility of SBR modified asphalt by addition of polyphosphoric acid (PPA)," Construction and Building Materials, vol. 139, pp. 183-192, 2017.

[25] F. Zhang, C. Hu, and Y. Zhang, "The effect of PPA on performances and structures of high-viscosity modified asphalt," Journal of Thermal Analysis and Calorimetry, vol. 134, no. 3, pp. 1729-1738, 2018.

[26] H. Zhang, Z. Chen, G. Xu, and C. Shi, "Physical, rheological and chemical characterization of aging behaviors of thermochromic asphalt binder," Fuel, vol. 211, pp. 850-858, 2018.

[27] O. M. Olabemiwo, A. O. Esan, G. O. Adediran, and H. O. Bakare, "The performance of Agbabu natural bitumen modified with polyphosphoric acid through fundamental and fourier transform infrared spectroscopic investigations," Case Studies in Construction Materials, vol. 5, pp. 39-45, 2016.

[28] J. Du, C. Ai, S. An et al., "Rheological properties at low temperatures and chemical analysis of a composite asphalt modified with polyphosphoric acid," Journal of Materials in Civil Engineering, vol. 32, no. 5, Article ID 04020075, 2020.

[29] T. Pan, Y. Lu, and S. Lloyd, "Quantum-chemistry study of asphalt oxidative aging: an XPS-aided analysis," Industrial \& Engineering Chemistry Research, vol. 51, no. 23, pp. 79577966, 2012.

[30] G. Fu, Y. Zhao, and Q. Sun, "Modification mechanisms of polyphosphoric acid and SBS on asphalt," Acta Materiae Compositae Sinica, vol. 34, no. 6, pp. 1374-1380, 2017.

[31] D. O. Larsen, J. L. Alessandrini, A. Bosch, and M. S. Cortizo, "Micro-structural and rheological characteristics of SBS- 
asphalt blends during their manufacturing," Construction and Building Materials, vol. 23, no. 8, pp. 2769-2774, 2009.

[32] J. Lamontagne, P. Dumas, V. Mouillet et al., "Comparison by Fourier transform infrared (FTIR) spectroscopy of different ageing techniques: application to road bitumens," Fuel, vol. 80, no. 4, pp. 483-488, 2001.

[33] Y. Zhang, "Study on the effect of PPA and sulfur on the performance of polymer modified asphalt," Master thesis, Fuzhou University, Fuzhou, China, 2017. 